\title{
PERIODICITY IN EVOLUTIONARY TRENDS OF PLANKTIC FORAMINIFERA: FACTS AND CAUSES
}

\author{
LONGORIA, José F.; GAMPER, Martha A., Florida International University, University Park. \\ PC344, Miami, FI. 33199
}

The phylogenetic development of planktic foraminifera from Aptian through Priabonian (83.3 $\mathrm{ma}$ ), is characterized by marked cyclical morphological changes that allow the recognition of periodic iterative evolutionary trends. These changes resulted in identical evolutionary phases (I through IV in figure 1) in three separate clades: ticinellids, globotruncanids, and globorotallids. These evolutionary phases are linked to heterochrony and include: (I) regression (reduction or increase in size) whereby planktic foraminifera recapitulate their globular non-keeled ancestors.

(II) experimentation (sudden changes in morphology without defined patterns) whereby planktics undergo abnormal morphological variations resulting in monstrosities whose taxonomic position is at best classified as incertae sedis. (III) development (acquisition of new stable morphologic characters) whereby planktics morphology becomes stable; evolutionary novelties for particular groups develop; the taxonomic position of new taxa is stable so new genera are recognized. (IV) differentiation (appearance of evolutionary novelties) whereby speciation and diversification of taxa take place; a proliferation of species is recognized. The recurrence of the aforementioned evolutionary stages defines three cycles of planktic foraminiferal iterative evolution: (1) Aptian-Cenomanian (28.2 ma); (2) TuronianMaastrichtian (25.1 ma); and (3) DanianPriabonian (29 ma). These events had a profound transformation of planktic morphology resulting in the recognition of unique morphogroups with interrelated taxa.

The duration of each evolutionary phase varies from cycle to cycle but the succession of evolutionary phases within each cycle remains constant. The recurrence of the regression phase indicating the beginning of a new cycle, seems to indicate a periodicity of an average of about 27.3 ma. In spite of discrepancies in the time interval applied to different geologic time scales, our results indicate that the periodicity of planktic

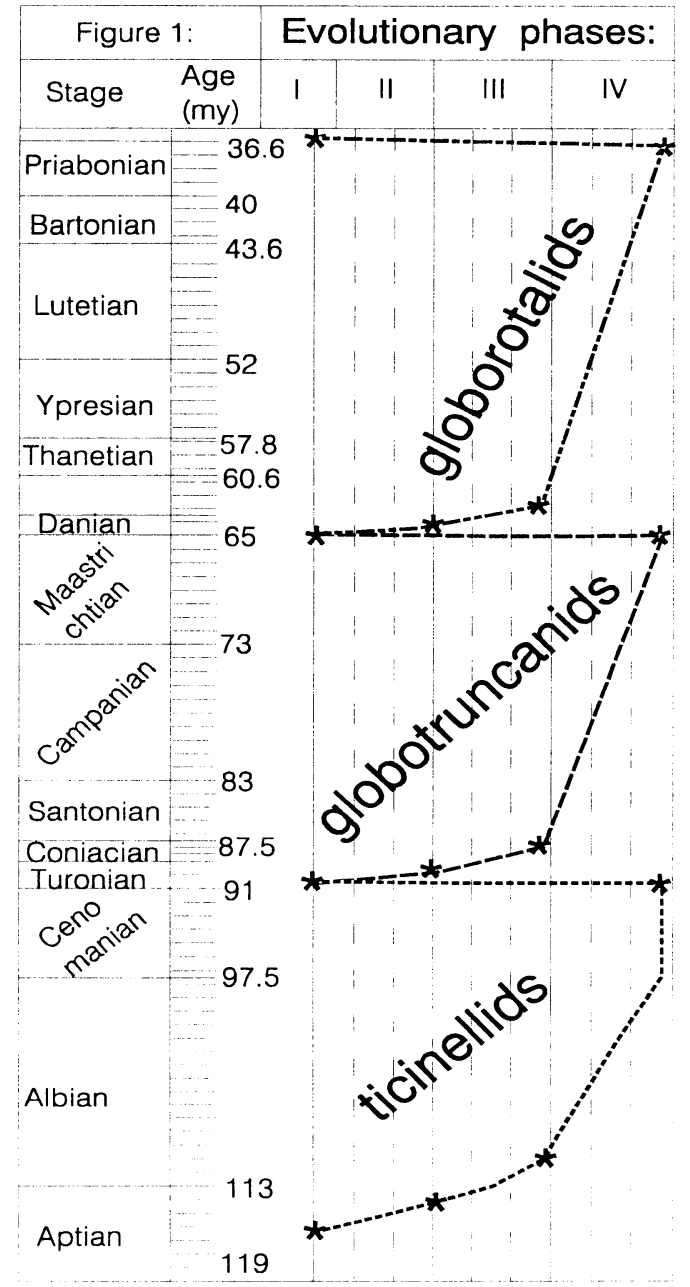
foraminiferal evolutionary cycles should be linked to global phenomena as the cause of the biological transformation. The coincidental occurrence of planktic foraminiferal transformations and the postulated periodicity of extraterrestrial impacts invites to investigate the correspondence of these two events at different geologic times. With the exception of the Aptian, the initial stages of the other cycles clearly demonstrate that from the biological viewpoint, these evolutionary cycles observed in planktic foraminifera involve a transformation of taxa from highly complex morphology into a simpler morphology, involving a phylogenetic transformation reflected in the test periphery as follows: globular test $\rightarrow$ laterally compressed test $\rightarrow$ keeled test. 